\title{
REINVENTANDO AS PRÁTICAS PSI
}

\author{
Maria Lívia do Nascimento \\ Juliane Macedo Manzini \\ Fernanda Bocco \\ Universidade Federal Fluminense
}

\begin{abstract}
RESUMO: A proposta do presente artigo é problematizar o lugar legitimado de saber/poder do psicólogo. Para tanto, partiremos de nossa prática acadêmica, quer seja como professora, estudante de graduação, estagiária, extensionista ou supervisora para colocar em análise a produção do profissional especialista em atribuir significados aos processos de vida. Apostamos, a partir das idéias de Foucault, na provisoriedade das verdades e na possibilidade de criação e de invenção, contrariando as naturalizações e dicotomizações presentes na formação e atuação em psicologia.
\end{abstract}

PALAVRAS-CHAVE: práticas psi; formação em psicologia; psicologia e política.

\section{REINVENTING THE PSY PRACTICES}

ABSTRACT: The purpose of this article is to criticize the legitimated role of knowledge/power played by Psychologists. In order to do so, we will start our work based on our academic practices, whether as teachers, students, trainees, extension service professionals, or supervisors, to analyze the production of a kind of professional who specializes on assigning meanings to the processes of life. We believe, based on Foucault's ideas, in the temporariness of truths and in the possibilities for creation and invention, opposing the naturalizations and dichotomizations so common on current psychological studies and practices.

KEYWORDS: psy practices; psychology education; psychology and politics.

Dentre as ciências humanas e sociais que emergem no século XIX, é possível encontrar a Psicologia, a qual se afirma, principalmente, a partir de dois saberes, o de observação e o clínico, ambos sustentados por crenças em verdades imutáveis e universais e, portanto, a-históricas e neutras. Baseada em tais princípios, a formação $p s i$ é pontuada por discursos e práticas que acreditam na apreensão objetiva do mundo e do ser humano, na natureza específica e identitária dos objetos e nas dicotomias. Por isso são tão freqüentes, no campo da psicologia, os binarismos que opõem objetos, conceitos, territórios como teoria e prática, saber e poder, indivíduo e sociedade, macro e micro, interior e exterior, dentre outros. Dessa maneira, psicologia e política têm sido construídas e aceitas, de um modo geral, como territórios separados e em oposição. ${ }^{1}$

Partindo de tais questões, pretendemos aqui discutir essa dicotomia entendendo psicologia e política como planos que se cruzam, que se atravessam, que se complementam, que são múltiplos e impossíveis de serem apreendidos em sua totalidade. Nos interessa interrogar como os domínios da psicologia e da política, obrigatoriamente atravessados entre si, estão presentes nos espaços de formação e atuação dos psicólogos. Para isso, é necessário tomarmos a prática psi como uma prática implicada, que atua na potência política da vida.

Nossa reflexão pode ser iniciada com uma pergunta colocada por Mello (1999, p.10): "Será possível olhar as pessoas, sentir o cheiro das gentes, molhar-se nas águas da pobreza das ruas e ainda assim estar falando de psico- logia?". Ao nos colocar tal indagação, a autora faz uma provocação a determinadas práticas psicológicas pautadas na neutralidade científica, onde o psicólogo não se mistura com o seu objeto, ao contrário, busca se distanciar dele, apresentando respostas cheias de certezas, acreditando-se capaz de prever comportamentos.

Salvo algumas exceções, a formação em psicologia vem sendo freqüientemente regulada por esse modelo, primando pela produção de especialistas sem se preocupar em construir dispositivos que coloquem em análise tal paradigma. No entanto, as experiências de estágio, as práticas de extensão, as supervisões e os debates presentes em sala de aula podem ser espaços privilegiados para a experimentação e a construção de uma psicologia que não se separa da política, nem da vida. Em nossa atuação acadêmica, quer seja como professora, estudante de graduação, estagiária, extensionista ou supervisora, temos participado de projetos que tomam a própria prática do psicólogo como questão. Neles, nem todas as atividades a serem realizadas estão a priori definidas, sendo elas construídas e decididas a cada momento. Entretanto, isso não significa um fazer sem critério nem direção, o trabalho se apóia em um saber que vai se fazendo no coletivo da própria prática. Nos guiamos pela lógica do agenciamento proposta por Deleuze e Parnet (1998), na qual diagramas e traçados vão se compondo a partir da multiplicidade presente em toda e qualquer realidade.

As ações clínicas, pedagógicas e políticas não se separam umas das outras, sendo qualquer intervenção, por 
mais insignificante que pareça, considerada essencialmente política, uma vez que sempre provoca efeitos no coletivo e repercute no projeto como um todo. Em diversas ocasiões, assumimos tarefas tidas como administrativas e distantes da atuação do psicólogo, tais como acompanhar um jovem para inscrição na escola, auxiliar na marcação de consultas médicas, orientar solicitações de documentos, etc. Assim, a psicologia não precisa, necessariamente, estar inscrita em uma fórmula, podendo acontecer através de qualquer atividade que seja necessária num determinado momento.

Lancetti (1992, p.97) nos fala da importância da ruptura da identidade profissional como um método constante. Discutindo uma intervenção por ele realizada na Casa de Saúde Anchieta, em Santos (SP), relata que a equipe interventora decidiu suprimir o uso dos consultórios de psicologia, buscando a invenção de outras formas de relação com os internos como, por exemplo, sugerindo aos profissionais que fossem ao pátio e se engajassem na tarefa de cortar unhas. Essa proximidade física poderia estabelecer um diálogo, reconstruindo a história de pacientes cronificados e estabelecendo uma condição profissional na qual seria possível "desestruturar a noção do que vinha a ser fazer psicologia em uma instituição".

Sabemos que sair das certezas que a formação tradicional oferece não é tarefa fácil e nem ocorre sem crises. Não ter um lugar seguro onde se apoiar gera dúvidas, angústias e medos, ao passo que ter acesso, já a partir da graduação, a experiências que reinventem a psicologia é fundamental para construir autonomia e segurança nas decisões e análises. Nessa proposta de dar espaço para a emergência de outras psicologias temos participado de experiências atentas aos diferentes sentidos produzidos no campo da intervenção, às possibilidades de desvios, ao lugar instituído do psicólogo.

Uma dessas intervenções se deu em um Conselho Tutelar, como atividade de estágio de alunos do curso de formação em psicologia. A proposta visava desindividualizar o atendimento das famílias que chegavam ao conselho, construir situações coletivas de trabalho e convocar para a formulação de políticas públicas no município. Dessa maneira, o estágio incluía a participação em diversos fóruns de defesa dos direitos da infância e da juventude, tais como o Conselho de Direitos e o Fórum Municipal de Defesa dos Direitos da Infância e da Juventude, lugares onde prioritariamente são construídas as políticas de atendimento à criança e ao jovem. A idéia consistia em fazer os alunos pensarem que participar de um estágio de psicologia é também participar de fóruns de decisões políticas, é se incluir na discussão da questão dos Direitos Humanos, dos movimentos sociais e da produção da violência urbana, retirando o psicólogo do lugar do assistencialismo e do atendimento pontual e envolvendo-o num cotidiano de indagações éticopolíticas.
Uma outra intervenção ocorreu em um projeto com jovens autores de infração, no qual a psicologia (estagiária e supervisora acadêmica) trabalhava junto à equipe local e com os jovens diretamente. A intervenção da estagiária consistia em acompanhar o dia a dia do projeto, assim como participar das reuniões da equipe, oferecer encontro em grupo com os jovens semanalmente e manter contato com as unidades de internação de onde eram encaminhados os participantes do projeto. Também participava das reuniões semanais com a supervisora e colegas de estágio para discussão e análise da intervenção e de suas implicações na intervenção. Em meio ao cotidiano do trabalho, convivendo com os desejos e os afetos dos jovens e tentando acolher maneiras emergentes de sentir e de pensar, a estagiária foi abandonando o fazer conhecido da psicologia e produzindo outros territórios ao "sair da noção disciplinar de tarefas a serem cumpridas", ao estar atenta "a como as coisas aconteciam na prática e não achar que "nada foi produzido' por não haver saído como planejado" (Bocco \& Lazzarotto, 2004, p.43).

Nesses dois exemplos, encontramos situações de desterritorialização que dão condição de existência a uma outra psicologia. Guillier (2004, p.14), ao comentar a idéia da prática implicada, diz que "é preciso se abrir ao máximo para os acontecimentos que aparecem e que garantem os desvios, para o acaso dos encontros, para as associações". Veyne (1982, p.151) nos lembra que Foucault não pensava em termos de estrutura, corte ou discurso, mas sim em termos de raridade (acontecimento): "os fatos humanos são raros, não estão instalados na plenitude da razão, há um vazio em torno deles para outros fatos que o nosso saber nem imagina. O que é poderia ser diferente. Os fatos humanos são arbitrários, não são óbvios".

Para pensarmos uma psicologia que se movimenta e constantemente atualiza suas práticas, é preciso conceber que as questões ligadas a ela são mais amplas do que o território do indivíduo, de fato dizem respeito a uma multiplicidade de sentidos sociais, políticos e históricos. As análises construídas aqui se apóiam nos fazeres que viemos realizando junto a estabelecimentos ligados à justiça da infância e da juventude (Juizados, Ministério Público), àqueles responsáveis pelo atendimento da população infantojuvenil no que diz respeito à proteção de seus direitos (Conselhos Tutelares) e a projetos que atendem jovens em cumprimento de medida sócio-educativa fora do local de internação, em caráter de trabalho educativo. ${ }^{2}$ Nos espaços do Conselho Tutelar e do Juizado, o atendimento de uma família é atravessado, entre outras coisas, pelas políticas econômicas do município, pela história da assistência brasileira, pelos conflitos sociais, etc. Atender as crianças enviadas pela escola com o rótulo de dificuldade de aprendizagem, atribuindo-lhes diagnóstico de falha cognitiva, de desinteresse, é desconsiderar as múltiplas formas que foram construindo o chamado "fracasso escolar". Também 
no trabalho com jovens autores de infração, a psicologia tende à culpabilização individual, criminalizando o jovem em si ao desconsiderar os processos coletivos de produção de subjetividade.

Nesses casos, o que pode a psicologia? Ou age dentro de suas propostas modelares, calcadas nos especialismos técnico-científicos, na identificação de casos clínicos, ou percebe que "o homem, a sociedade, a psicologia e a política não são. Sempre estão sendo, sempre estarão se fazendo" (Coimbra \& Leitão, 2003, p.9). No primeiro caso, o psicólogo aparece como o profissional que traz a solução dos problemas, sendo ele capaz de dar a última e verdadeira palavra, de transformar as personalidades. ${ }^{3} \mathrm{~A}$ segunda opção possibilita uma psicologia que busca desvios e inventa caminhos nunca imaginados, imprimindo análises a partir de um conjunto de diferentes lógicas, recusando o lugar da solução de problemas imediatos e atuando no inusitado dos acontecimentos. Para tanto, a análise de implicações deve ser a ferramenta constante de seus profissionais.

O paradigma da implicação permite mostrar as diferentes forças presentes no campo de atuação, fazendo, em muitos momentos, emergir acontecimentos e propiciando análises. De acordo com Lourau (1993), a análise de implicações traz para o campo da intervenção sentimentos, percepções, ações e acontecimentos até então considerados negativos, estranhos, tidos como erros que impediriam uma prática de ser bem-sucedida. Colocar em análise o lugar que ocupamos, nossas práticas de saber-poder enquanto produtores de verdades - consideradas absolutas, universais e eternas - seus efeitos, o que elas põem em funcionamento, com o que se agenciam é romper com a lógica racionalista presente no pensamento ocidental, a qual evoca a neutralidade do profissional. Ao seguir tal pensamento, não seria possível a existência do psicólogo apolítico, pois toda e qualquer prática por ele perpetrada é sempre implicada, produz efeitos, é sempre política.

\section{Psicologia e política: encontros}

O psicólogo é alguém que conhece o homem: para que estuda propriamente os homens? Ele quer retirar deles pequenas vantagens, ou mesmo grandes - ele é um político!... Este aí também é um conhecedor dos homens: e vós dizeis que ele não quer com isso nada para si, que ele é um grande "impessoal". Atentai mais incisivamente! Talvez ele ainda queira até mesmo uma vantagem pior: sentir-se superior aos homens, ter o direito de olhar para eles desde cima, não se misturar mais com eles. (Nietzsche, ano, p.)

Já no século XIX, Nietzsche (1988) percebia a estreita ligação existente entre psicologia e política. Considerava que a ação do psicólogo, assim como a do político, não podia ser pensada como neutra nem isenta de poderes, já que os dois estudam o homem para "retirar deles pequenas vantagens". Ironicamente, as próprias práticas psi têm se empenhado, com insistência, em dissociar essas duas esferas, numa busca incansável por atingir a imparcialidade no setting terapêutico.

Esse ideal do profissional imaculado não surgiu ao acaso, pelo contrário, apareceu vinculado a um processo histórico que produziu uma determinada noção do que deveria ser a psicologia. No início, quando começou a formar-se enquanto campo específico, esforçou-se por atingir um status de objetividade e rigor, priorizando o psi cientista sobre o psi sujeito no mundo (na cidade, polis) na busca do ideal de ciência. Mais adiante, com o surgimento da psicanálise no fim do século XIX, insistiu-se na importância de que o analista estivesse desprovido de suas questões pessoais no atendimento, uma vez que era condição fundamental sua suposta neutralidade para que o paciente pudesse projetar de forma satisfatória suas questões inconscientes. Desse modo, a psicologia foi fazendo uma trajetória na qual não parecia haver lugar para o psicólogopolítico, implicado com as questões de sua época e atento aos efeitos dessas implicações em sua prática.

Mas, apesar de ainda ser predominante o profissional que não tem por hábito analisar suas práticas, outra forma de inserir-se no mundo foi tomando força a partir de vários movimentos ocorridos nas décadas de 1950 e 1960. Diversos profissionais exerceram e defenderam o lugar do cientista implicado nas questões sociais pertinentes à sociedade na qual ele existe. Freire (1997, p.86), para não ir muito longe, dizia que seu "papel no mundo não é só o de quem constata o que ocorre mas também o de quem intervém como sujeito de ocorrências".

A partir da Segunda Guerra Mundial e, mais intensamente, nos acontecimentos que culminaram com o Maio de 68 na França, tensionou-se a discussão sobre a parcialidade do intelectual e o partido tomado por ele diante dos dilemas de seu tempo. Sartre, que defendeu o modelo do intelectual engajado, celebrizou este debate ao defender que o intelectual-escritor não é neutro diante da realidade histórica e social. “O escritor 'engajado' sabe que a palavra é ação: sabe que desvendar é mudar e que não se pode desvendar senão tencionando mudar", enfatiza (Sartre, 1993, p.20).

Na verdade, os intelectuais sempre foram o que Freire chamou sujeito de ocorrências já que, de uma forma ou de outra, serviram a interesses os mais diversos com seus fazeres, mesmo com a pretensa distância que buscavam ter de qualquer postura dita ideológica. ${ }^{4} \mathrm{O}$ problema é que, com a preocupação de manter-se afastados das esferas públicas, esses intelectuais muitas vezes foram usados por poderes hegemônicos para a manutenção do status quo, e seguiam mantendo suas ações sem perceber os efeitos destas. 
Nas palavras de Silva,

O especialista apolítico se considera neutro e imparcial. Ele é capaz de dissertar sobre a miséria humana com a sensibilidade de um autômato; é capaz de escrever sobre os avanços tecnológicos sem se colocar uma simples questão: a quais interesses servem a técnica e a ciência? O especialista desconsidera a dialética da relação indivíduo e sociedade (isola um dos pólos ou toma-os de forma dicotômica); não percebe que todo saber expressa interesses e relações de poder. Ao mínimo lampejo de consciência infeliz ele recorre à filantropia ou aos argumentos psicologizantes, individualizando os problemas de caráter social. Termina por culpabilizar a vítima. (Silva, 2003, não paginado)

Depois do 11 de setembro, ${ }^{5}$ evento-símbolo de uma época na qual a paranóia pela segurança toma proporções inéditas, é impossível afirmar que o medo, a angústia e a solidão possam remeter apenas a questões apenas internas e individuais. No atual contexto da sociedade capitalista, não podemos seguir mantendo o sonho da imparcialidade diante da condição humana. Desde a construção da bomba atômica, ficou evidente que o conhecimento científico não é puro nem alienado dos processos político-sociais nos quais é produzido. Também ficou evidente o quão desastrosos podem ser os resultados de uma prática que não se questione sobre os efeitos que provoca no mundo.

Contestamos com veemência a postura do psicólogo dito apolítico, bem como suas práticas alienadas e alienantes que enfatizam a esfera interna e particular como domínios únicos da realidade. Como expressa Passos, o que temos é de fazer

redes públicas que envolvem a dimensão coletiva da existência e que estão comprometidas em processos de produção de subjetividades não dominadas pelo pânico, pela dívida, pela depressão. Este é o compromisso clínico-político que nos anima. (Passos, s/d, pp.8-9)

A inseparabilidade entre psicologia e política pensada por nós em nossa atuação problematiza os especialismos técnico-científicos e permite a interlocução entre temas até então tidos como inconciliáveis. Cabe ao psicólogo participar das discussões políticas do Fórum Municipal de Defesa dos Direitos da Infância e da Juventude? Deve ele atuar nos movimentos sociais que se contrapõem à redução da maioridade penal? Está fazendo psicologia quando interpela autoridades governamentais que tentam solucionar as rebeliões da FEBEM fornecendo parcos auxílios financeiros às famílias dos internos que não participarem desses movimentos? ${ }^{6} \mathrm{~A}$ esse conjunto de questões só nos cabe responder afirmativamente, porque negamos as essências desses diferentes territórios e apostamos que suas constituições históricas se articulam sobremaneira com o campo da psicologia.
Não cremos ser possível trabalhar com as questões mencionadas - ou com qualquer outra - sem levar em conta a realidade político-econômica que as atravessa. Fazer psicologia é imediatamente fazer política, pois lidamos com sujeitos que habitam um determinado momento e lugar históricos, e não há distância nem oposição entre indivíduo e sociedade, mas uma economia subjetiva e política que estão indissociadas (Benevides, 2002). O fazer da psicologia não apenas acolhe sujeitos e formas de ser, mas também produz subjetividades, reforçando ou questionando, favorecendo ou constrangendo, em uma constante interferência com o plano político.

\section{A Formação psi em questão}

A psicologia, como anteriormente assinalado, presentificase desde meados do século XIX e início do século XX como um domínio de saber que se propõe estudar questões relativas à constituição do homem e sua relação com o mundo, configurando-se enquanto área de conhecimento que propicia a adaptação e o ajustamento do indivíduo consigo mesmo, com os demais e com o próprio meio no qual está inserido. A partir desta perspectiva, a psicologia contribui na modelagem de uma determinada forma-homem, concebendo-o como um ser universal, possuidor de uma natureza humana ou de uma essência fixa, dotado de capacidades psíquicas, processos e potencialidades em desenvolvimento linear no contexto social.

Alicerçada pelo pensamento positivista, pelo método experimental e sob forte influência das tendências estadounidenses, esta nova disciplina abriu passagem para a emergência de diversas matrizes e sistemas psicológicos, resultando inicialmente na estruturação de territórios esquadrinhados como a psicologia do trabalho, a psicologia clínica e a psicologia escolar. Em decorrência de tais abordagens, a prática psicológica assumiu nitidamente um perfil com características de neutralidade, objetividade, experimentação e tecnicismo, reproduzindo muitas vezes conceitos e procedimentos diagnósticos que buscavam facilitar o campo de intervenção do psicólogo, bem como prevenir e até mesmo eliminar os possíveis comportamentos considerados desviantes e conflitantes.

Especificamente no Brasil, a psicologia se tornou uma profissão oficialmente reconhecida enquanto espaço de formação profissional somente em 1962. Como nos apontam Rocha, Montano, e Pimenta (2001), com a regulamentação da profissão proliferaram os cursos universitários de formação de psicólogos, possibilitando o surgimento de metodologias e tecnologias mais refinadas, porém prevalecendo os mesmos princípios formulados no início do século passado. No entanto, é a partir de 1970 que se observa uma expansão das práticas psi no país, com a predominância de um enfoque estritamente ligado ao atendimento em consultório. Ou seja, uma determinada clínica vem sendo produzida e forjada nos cursos de graduação de psicologia, 
pautada pela psicologização do cotidiano e da vida, descontextualizando as questões sociais e reduzindo-as a aspectos de ordem psicológica e individual (Coimbra, 1995). Mesmo hoje, e em grande medida, este modelo clínico hegemônico se materializa nos consultórios particulares e nos diversos estabelecimentos públicos, pondo em funcionamento práticas de individualização e de intimização que têm como efeitos o recorte e a delimitação do homem em dois pólos distintos, reafirmando a dualidade existente entre indivíduo e sociedade.

Em relação à formação em psicologia, Josephson e Neves nos alertam:

Nos cursos de formação de psicólogos, ainda é majoritária a difusão de posturas clínicas que reproduzem, acriticamente, as clássicas dicotomias interior/exterior, consciente/inconsciente, sujeito/objeto, clínical política, e tantas outras, porém procurando ajustálas aos "novos tempos" e às "novas doenças", criando "novas técnicas". (Josephson \& Neves, 2002, p.99)

As autoras chamam a atenção para a emergência de uma diversidade de síndromes e compulsões que estão em cena na contemporaneidade e que têm requerido revisões e reformulações de saberes psicológicos presentes nos estabelecimentos de ensino. Dentre as chamadas "novas doenças da alma" - fobia social, transtorno de ansiedade generalizada (TAG), síndrome do pânico, transtorno obsessivo-compulsivo (TOC), distúrbios alimentares e toxicomanias - o psicólogo vem investindo em distintos cursos de capacitação e treinamentos, com a justificativa de obter conhecimentos suficientes para resolver tais sofrimentos psíquicos. Assim, buscar diferentes métodos e estratégias eficazes tem sido um movimento constante que acompanha o exercício profissional do psicólogo. Diante deste cenário, antigos sistemas teóricos são abandonados. $\mathrm{Ou}$ ainda, procedimentos terapêuticos considerados por muito tempo como insatisfatórios ou até mesmo ultrapassados ressurgem de forma reelaborada, servindo como alternativa para a supressão das anomalias. Freqüentemente, estes se aliam à administração de medicamentos na busca de atender às novas exigências de tratamento para os transtornos da vida contemporânea.

Soluções a curto prazo, discursos e saberes avançados. O mundo globalizado tem exigido um trabalhador cada vez mais flexível, qualificado, competente e adaptado às necessidades advindas do mercado, intensificando a emergência do técnico especialista. Em nome de aumentos de produtividade, de eficiência e da eficácia técnica, os espaços de formação atrelados à lógica do capital fortalecem e forjam profissionais supostamente capacitados a dar respostas competentes, tornando-os consumidores ávidos por produtos e serviços especializados e bem definidos. Nessa lógica insere-se, também, o campo de atuação do psicólogo. O mesmo movimento que legitimou e regulamentou o exer- cício da profissão no Brasil também instituiu o título profissional de especialista em psicologia, circunscrevendo o trabalho em diversas áreas. ${ }^{7}$ Portanto, ao aprovar cada nova especialidade, delimita-se a prática dos psicólogos em conhecimentos específicos, produzindo assim domínios de saber demarcados.

Os territórios de formação acadêmica vêm sofrendo uma profunda alteração nos últimos anos visando acompanhar a rapidez das informações e das inovações teóricometodológicas. Estes espaços, em especial o campo da psicologia, vem insistindo "no caráter de uma formaçãoconsumo" (Heckert, 2000), ou seja, uma formação onde a aquisição por técnicas e conhecimentos deve ser permanente. Neste sentido, desconsiderando muitas vezes o contexto sócio-histórico-político nos quais estão inseridos, nossos cursos acabam por gerar profissionais que de certa forma reproduzem acriticamente métodos e procedimentos, não percebendo a possibilidade de uma atuação crítica e inventiva.

Pensar a reinvenção das práticas psi diante desse quadro implica uma constante resistência a essa lógica que tenta mostrar uma única forma de fazer psicologia, tecnicista e compartimentada. É preciso sair do fazer sobre-implicado que a lógica produtiva procura impor ao promover um sobretrabalho e ativismo da prática que terminam por impossibilitar as análises sobre nossos fazeres e implicações. ${ }^{8}$ Propomos adotar um constante estranhamento dos paradigmas e realidades que se apresentam como prontos, autorizando-nos a inventar, no cotidiano, estratégias que não obedeçam às fórmulas prescritas mas que, pelo contrário, possibilitem o exercício de autonomia em nossas análises e gestões do dia a dia.

\section{Notas}

1. A respeito ver Coimbra, C. e Nascimento, M.L. (2001).

2. De acordo com a Lei n. 8.069, de 13 de julho de 1990, que dispõe sobre o Estatuto da Criança e do Adolescente (ECA), no artigo $68 \S 1^{\circ}$, o trabalho educativo se refere a uma atividade na qual se privilegia o aspecto de aprendizagem e o desenvolvimento pessoal e social sobre $o$ aspecto produtivo, mesmo quando houver remuneração pelo trabalho efetuado.

3. Em pesquisa realizada pelo projeto PIVETES (Nascimento, 2002) em processos do Juizado da Infância e da Juventude, o mais comum é que o psicólogo seja chamado a atuar nos casos considerados de difícil solução.

4. Coimbra (1995) nos mostra muito bem como as práticas psi colaboraram com a ditadura no Brasil. Esses profissionais realizavam laudos nos quais reduziam as posturas políticas contestadoras dos sujeitos a distúrbios de comportamento, culpabilizando as famílias.

5. No dia 11 de setembro de 2001 houve um ataque supostamente terrorista contra as torres do World Trade Center em Nova Iorque, ocasionando milhares de mortes.

6. Em 18 de março de 2005, em função das inúmeras rebeliões nas FEBEM de São Paulo, o governador Geraldo Alckmin anunciou 
proposta de concessão de $\mathrm{R} \$ 60,00$ mensais às famílias dos internos que apresentarem "bom comportamento" na unidade 7.

7. Conforme a resolução do CFP (2000) n $n^{\circ} 014 / 00$ no art. $3^{\circ}$, as especialidades a serem concedidas são as seguintes: psicologia escolar/educacional, psicologia organizacional e do trabalho, psicologia de trânsito, psicologia jurídica, psicologia do esporte, psicologia hospitalar, psicologia clínica, psicopedagogia e psicomotricidade.

8. Sobre o assunto, consultar texto de Coimbra e Nascimento (2004).

\section{Referências}

Benevides, R. (2002). Clínica e Social: polaridades que se opõem/ complementam ou falsa dicotomia? In: Rauter, C., Passos, E. \& Benevides, R. (Eds.), Clínica e Política: subjetividade e violação dos Direitos Humanos (pp.123-140). Rio de Janeiro: Te Cora, pp. 123-140.

Bocco, F. \& Lazzarotto, G.D.R. (2004). (Infr)Atores juvenis: artesãos de análise. Psicologia \& Sociedade, 16, 2, 37-46.

Coimbra, C. (1995). Guardiães da ordem: uma viagem pelas práticas psi no Brasil do milagre. Rio de Janeiro: Oficina do Autor.

Coimbra, C. \& Nascimento, M.L. (2001). O efeito Foucault: desnaturalizando verdades, superando dicotomias. Psicologia: Teoria e Prática, 17, 245-248.

Coimbra, C. \& Nascimento, M.L. (2005). Sobreimplicação: práticas de esvaziamento político? Niterói: Universidade Federal Fluminense, 2004. Disponível em: http://www.slab.uff.br/exibetexto2. php?link $=\% 2$ Ftextos $\% 2$ Ftexto 22. htm \& codtexto $=22 \& \operatorname{cod}=22 \&$ tp=t\&nome_autor=>. Acesso em: 13/06/2005.

Coimbra, C., Leitão, M.B.S. (2003). Das essências às multiplicidades: especialismo psi e produções de subjetividades. Psicologia e Sociedade, 15, 6-17.

Conselho Federal de Psicologia (2000). Resolução n ${ }^{\circ}$ 014, 20 de dezembrode 2000. Brasília, 2000. Disponível em: <http://www.pol.org.br/ legislacao/leg_resolucoes2000.cfm>. Acesso em: 11/06/2005.

Deleuze, G. \& Parnet, C. (1998). Diálogos. São Paulo: Escuta.

Freire, P. (1997). Pedagogia da Autonomia: saberes necessários à prática educativa. São Paulo: Paz e Terra.

Guillier, D. (2004). Comentando as noções de "implicação e transdução" de René Lourau. Revista do Departamento de Psicologia (UFF), 16, 11-16.

Heckert, A.L.C. (2000). Os desafios da educação na contemporaneidade. In: Barros, M.E.B. \& Silva, A.A. (Eds.), Psicopedagogia: alguns hibridismos possíveis. Vitória: Saberes Instituto de Ensino, pp. 11-18.

Josephson, S.C. \& Neves, C.A.B. (2002). A Crítica como Clínica. In: Machado, L.D., Lavrador, M.C.C. \& Barros, M.E.B. (Eds.), Texturas da psicologia: subjetividade e política no contemporâneo. São Paulo: Casa do Psicólogo, pp. 99-108.

Lancetti, A. (1992). Movimento do institucionalismo. In: Anais do $1^{o}$ Congresso Brasileiro de Psicologia da Comunidade e Trabalho Social (pp.95-99). Belo Horizonte: Organizador.
Lourau, R. (1993). Análise institucional e práticas de pesquisa. Rio de Janeiro: UERJ.

Mello, S.L. (1999). Prefácio. In Baptista, L.A. (Ed.) A cidade dos sábios (pp.). São Paulo: Summus, pp. 1-5.

Nascimento, M.L. (Org.), PIVETES: a produção de infâncias desiguais. Niterói: Intertexto; Rio de Janeiro: Oficina do Autor.

Nietzsche, F.W. (1988). Crepúsculo dos Ídolos ou a filosofia a golpes de martelo. Lisboa: Edições 70.

Passos, E. (s/d). Os dispositivos clínico-políticos e as redes no contemporâneo. EntreLinhas (CRP-07), 8-9.

Rocha, M.L., Montano, S.F., Pimenta, T.J. (2001). Pesquisas participativas e a pesquisa-intervenção na escola. In: Jacó-Vilela, A.M., Crezzo, A.C. \& Rodrigues, H.B.C. (Eds.), Clio-psyché hoje: fazeres e dizeres psi na história do Brasil (pp.251-259). Rio de Janeiro: Relume Dumará; FAPERJ.

Sartre, J.-P. (1993). Que é literatura. São Paulo: Ática.

Silva, A.O. (2003). Os intelectuais diante do mundo: engajamento e responsabilidade. Revista Espaço Acadêmico. n. 29. Outubro de 2003; Mensal.Disponível em <http://www.espacoacademico.com.br/ 029/29pol.htm>. Acesso em $07 \mathrm{dez} 2004$.

Veyne, P. (1982). Foucault revoluciona a história. Cadernos da Universidade de Brasília. Brasília: Editora da UNB.

Maria Lívia do Nascimento é professora do Departamento de Psicologia da Universidade Federal Fluminense, atuando na graduação e na pós-graduação. O endereço para correspondência é Departamento de Psicologia. Campus do Gragoatá, Bloco O, $2^{\circ}$ andar. 24210-350 - Niterói, RJ.

livianascimento@cruiser.com.br

Juliane Macedo Manzini é psicóloga formada pela Universidade Federal do Espírito Santo e Mestre pelo Programa de Mestrado em Psicologia da Universidade Ferderal Fluminense. jmmanzini@uol.com.br

Fernanda Bocco é psicóloga formada pela Universidade Federal do Rio Grande do Sul. Atualmente, é aluna do programa de mestrado em Psicologia da Universidade Federal Fluminense.

\section{fbocco@terra.com.br}

\section{Reinventando as práticas psi}

Maria Lívia do Nascimento, Juliane Macedo e Fernanda Bocco Recebido: 07/07/2005

$1^{\mathrm{a}}$ revisão: $13 / 11 / 2005$

Aceite final: 12/04/2006 